\title{
An isolated case of Legionnaires' disease
}

\author{
B. P. HARrold \\ M.D., F.R.C.P. \\ P. O. PYLE \\ M.B. B.S., F.F.A.R.C.S.
}

P. H. JONES

M.B. B.S., M.Sc.

E. O. UdEZUE

M.B. B.S.

\section{Luton and Dunstable Hospital, Luton, Bedfordshire}

\begin{abstract}
Summary
A single sporadic case of Legionnaires' disease which showed some unusual features is described from a young male who had never been out of the United Kingdom. The relevant literature is briefly reviewed.
\end{abstract}

\section{Introduction}

Single cases of severe or fatal illness of unknown cause are uncommon, but not rare. An outbreak of pneumonia in 182 people at a State American Legion Convention in 1976 gave the impetus for painstaking investigation of its cause, culminating in the demonstration of a Gram-negative bacillus previously unknown as a cause of human disease. Subsequently, and retrospectively, from use of stored sera, other outbreaks and single cases of pneumonia have been shown to be due to this agent. It seems to the present authors that with such a newly found disease, the full spectrum of its manifestations may not yet be known. It is for this reason that they produced this case report in some detail.

\section{Case report}

The patient was a Caucasian male aged 34 years who worked as a forklift driver, had not been out of the U.K. and was previously healthy, but smoked $114 \mathrm{~g}$ of tobacco in cigarettes per week. He became ill on 30 November, 1977, with fever, diarrhoea and a little vomiting. He had recovered from these symptoms by 3 December, but was still unwell. On 4 December he had pain in the chest, difficulty in breathing, fever and delirium. The next day he began talampicillin $250 \mathrm{mg}$ thrice daily. By the 7 December he was much worse and had difficulty feeding and taking tablets, he was restless and confused, and was sent to hospital.

He was seen to be confused, restless, dehydrated with a temperature of $39.5^{\circ} \mathrm{C}$, respiration rate of $30 / \mathrm{min}$ and a pulse of 120 . The BP was $110 / 70 \mathrm{mmHg}$. There was reduction of breath sounds in the right chest with a few rhonchi. The abdomen was distended and resonant. His chest radiograph showed consolidation of the upper lobe of the right lung. Other tests were as follows: $\mathrm{Hb}, 14.9 \mathrm{~g} / \mathrm{dl}$; total white cell count, $12.5 \times 10^{9} / 1$; polymorphs, $10.27 \times 10^{9} / 1$; lymphocytes, $2.7 \times 10^{9} / 1$; blood film showed a marked left shift with toxic granulation; blood urea was $17.5 \mathrm{mmol} / \mathrm{l}$; serum potassium, $3.1 \mathrm{mmol} / \mathrm{l}$; serum sodium, $129 \mathrm{mmol} / \mathrm{l}$; serum chloride, 93 $\mathrm{mmol} / 1$; serum bilirubin, $45 \mu \mathrm{mol} / 1$; total proteins $51 \mathrm{~g} / 1$; albumin, $26 \mathrm{~g} / \mathrm{l}$; alanine transaminase was $>$ 300 i.u. and the alkaline phosphatase 141 i.u. The The ECG showed sinus tachycardia but was otherwise normal.

The patient was treated with penicillin 2 million units i.v. 6-hourly, and i.v. fluids, on the assumption he had pneumococcal pneumonia. The next day, he was more drowsy and restless, he had produced no sputum. His $\mathrm{Po}_{2}$ was $6.8 \mathrm{kPa}(52 \mathrm{mmHg}) ; \mathrm{PCO}_{2}$, $3.1 \mathrm{kPa}(25 \mathrm{~mm} \mathrm{Hg}) ; \mathrm{pH} \mathrm{7.51}$. His BP had fallen to $80 / 45 \mathrm{mmHg}$.

He was transferred to the Intensive Therapy Unit and intermittent positive pressure ventilation (IPPV) was started via an endotracheal tube and the $\mathrm{PO}_{2}$ rose to $10.2 \mathrm{kPa}(77 \mathrm{~mm} \mathrm{Hg})$ and the $\mathrm{PCO}_{2}$ to 4.5 $\mathrm{kPa}(34 \mathrm{mmHg}$ ); the $\mathrm{pH}$ was $7 \cdot 39$. The following night, his temperature peaked to $41^{\circ} \mathrm{C}$. Over the next few days his state of consciousness was impaired more than could be accounted for by the sedation that he had been given; his blood urea had risen to a maximum of $32 \mathrm{mmol} / 1$ on the 9 December, and later fell. On 11 December, lumbar puncture produced normal cerebrospinal fluid (clear, colourless, no cells, no bacterial growth on culture, sugar $4.6 \mathrm{mmol} / 1$, blood sugar $7.0 \mathrm{mmol} / 1$, lactate $0.15 \mathrm{~g} / \mathrm{l}$ ).

On 13 December, Legionnaires' disease was considered a likely diagnosis and treatment was changed to erythoromycin $600 \mathrm{mg}$ 4-hourly i.v. A fairly generalized macular erythematous rash had developed, most obvious at sites of contact with bed clothes, and although this was not very typical for penicillin allergy, penicillin treatment was stopped. 
There was also some slight rectal bleeding on this day.

Three days later, there had been no obvious change, he remained febrile and was distressed when IPPV was stopped for more than one hr. Tracheal aspiration was producing mucopurulent material which grew Pseudomonas aeruginosa on culture, sensitive to gentamicin. Treatment with this drug $80 \mathrm{mg}$ twice daily began on 16 December. Metronidazole one $g$ thrice daily was also given orally from this date although there was no bacteriological evidence for anaerobic infection. By the 19 December, the haemoglobin had fallen to $7.8 \mathrm{~g} / \mathrm{dl}$, and 4 pints of whole blood were transfused. A tracheostomy was made on 21 December, and between this date and 28 December and in spite of clinical evidence of improvement, the white cell count rose from 11.4 to $30.0 \times 10^{9} / 1(78 \%$ polymorphs and $22 \%$ lymphocytes). IPPV was gradually withdrawn over the next 7 days and the tracheostomy closed on 3 January. Although there was continued fever and production of mucopurulent sputum, treatment with gentamicin, erythromycin and metronidazole was stopped on 4 January. This change in management made no difference to the appearance of the patient's temperature chart or to his tendency for gradual improvement. The course of the illness is summarized in Fig. 1.

The appearance of his chest radiography had not changed significantly by the end of December, but as gradual resolution of the opacity of the right upper lobe occurred, it was clear that several abscess cavities were present, these were seen first on 6 January, and later became more obvious; no fluid levels were seen in them. On 5 January, one sputum culture produced Klebsiella sp., this organism had not been grown previously or subsequently, and was sensitive to gentamicin.

On 18 January, he developed a swollen painful right testis, this pain and swelling increased over the next week and then subsided. There was no obvious change in his temperature which remained raised at levels varying between 37 and $38^{\circ} \mathrm{C}$, and urine culture was sterile. On 15 January he restarted metronidazole and on 23 January, he restarted gentamicin. By the 3 February, he had been afebrile for 5 days, his pulse rate, which had varied between 130-140/ min, had fallen to $120-130$. He left hospital and by the 29 March the radiological evidence of cavitation and consolidation had completely resolved, all drugs had been stopped on 30 January.

Paired sera had shown no change in titres for antibodies to Mycoplasma, mumps, $\mathrm{Q}$ fever, psittacosis, influenza A and B or cytomegalovirus. Blood cultures on 7, 13, 19 and 21 December were all negative. Repeated attempts were made to isolate the Legionnaires' agent from blood and sputum on
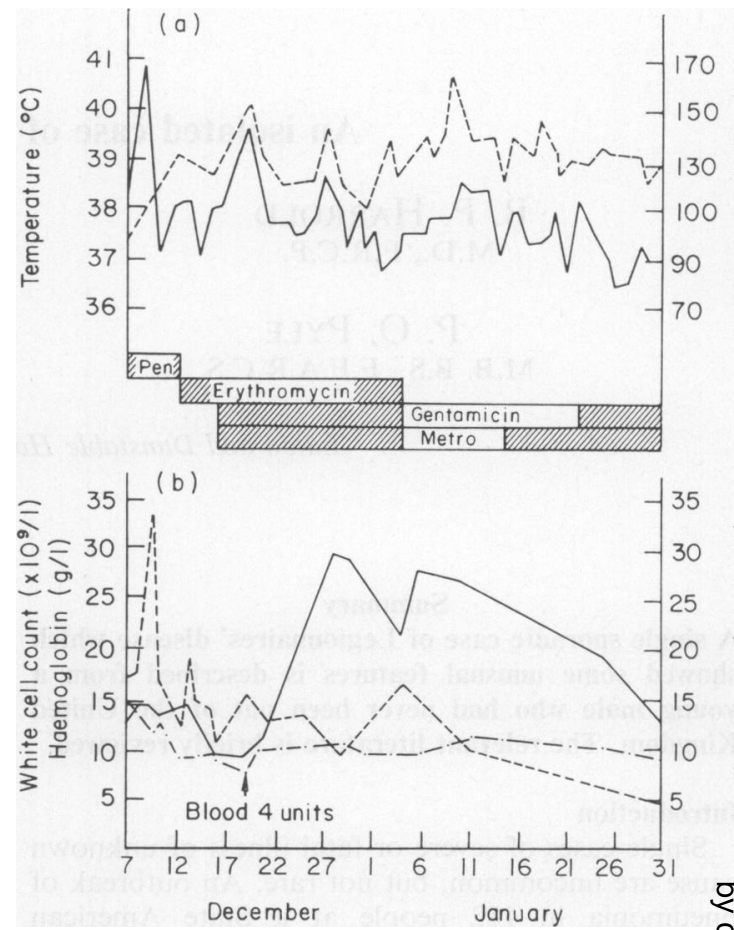

FIG. 1. Clinical course of patient with Legionnaires disease.

(a) - temperature, - - - pulse.

(b) - WBC, - - - urea, - - - - Hb.

Mueller-Hinton medium supplemented with Isovitalex and $\mathrm{Hb}$ without success.

Fluorescent antibody tests to Legionnaires, agent were performed on 5 consecutive sera from $\stackrel{\circ}{3}$ 13 December to 3 February by the Center for $\frac{3}{5}$ Disease Control, Atlanta, and the Standards Laboratory, Central Public Health Laboratory, Colindale. All sera were positive with titres of 1280 을 or 640. Complement fixing antibodies showed a rise from 64 on 13 December to 512 on 20 January.

\section{Discussion}

Legionnaires' disease has been described from at 0 least 325 patients in the U.S.A. (Fraser et al., 1977; U.S. Center for Disease Control, 1977) and a few in $\frac{7}{0}$ this country (Macrae and Lewis, 1977; Lawson et al., 1977; Ashford, Edmonds and Shanson, 1977). Sixty- o four of the American cases were isolated ones as $N$ were at least 3 of those in the U.K. (Lawson et al., N 1977; Ashford et al., 1977; Communicable Disease $\omega$ Surveillance Centre, 1977; Mitchell-Heggs, Jones and Groom, 1978). From the cases described in detail (Lawson et al., 1977) resolution of pulmonary $\stackrel{\Phi}{\oplus}$ disease usually began at about 10 days, but in the present patient there was no sign of radiological 
improvement until about 30 days after admission and at that time evidence of cavitation appeared. Between 14 and 20 days after admission, there was a dramatic rise in WCC to $30.0 \times 10^{9} / 1$, and a slight rise in temperature and pulse rate. Although frequent cultures were made, it was not until 28 days after admission that there was an isolated finding of Klebsiella sp. It is possible that the prolonged period of pulmonary consolidation leading to cavity formation was due to this organism but, if so, the infection began, and continued while gentamicin and erythromycin were being given. Sputum rarely became purulent in the 182 Legionnaires described by Fraser et al. (1977) and the presence of mucopurulent aspirate and later mucopurulent sputum in the present patient again suggests that an important secondary infection had occurred. The other unusual feature was the development of a painful swollen testis 42 days after admission. This resolved spontaneously, urine culture at the time and subsequent intravenous pyelography were normal. Very marked changes occurred in renal function and in liver function. These were transient and its seems likely that they were due to a general disturbance in metabolism caused by the pneumonia, perhaps in part due to intravascular coagulation. The urinary fibrin degradation products were elevated and the platelet count and haemoglobin were reduced at the height of the illness.

\section{References}

Ashford, R.F.U., Edmonds, M.E. \& Shanson, D.C. (1977) Legionnaires' disease in London. Lancet, ii, 1364.

Communicable Disease Surveillance Centre of the Public Health Laboratory Service (1977) Legionnaires' disease: first cases identified in England. British Medical Journal, 2, 1425.

Fraser, D.W., Tsai, T.R., Orenstein, W., Parkin, W.E., Beecham, H.J., Sharrar, R.G., Harris, J., Mallison, G.F., Martin, S.M., McDade, J.E., Shepard, C.C. \& BraChMAN, P.S. (1977) Legionnaires' disease: description of an epidemic. New England Journal of Medicine, 297, 1189.

LAwson, J.H., Grist, N.R., Reid, D. \& Wilson, T.S. (1977) Legionnaires' disease. Lancet, 2, 1083.

MACRAE, A.D. \& LewIS, M.J. (1977) Legionnaires' disease in Nottingham. Lancet, ii, 1225.

Mitchell-Heggs, P. Jones, P.W. \& Groom, G. (1978) Legionnaires' disease in London. British Medical Journal, 1, 236.

US Center for Disease Control. Atlanta, Georgia, Morbidity and Mortality Report 1977. 26, Nos. 2, 12, 14, $18,20,36,37,39,41,42,44$ and 45. 